\title{
Aplicación Murillo. Materialismo, charitas, populismo
}

Sevilla

Diciembre 2018-marzo 2019

\section{Institucionalizar el Barroco. Instrumentalizar la imagen}

Raro es no tener en algún cajón descuidado una estampa o almanaque que no lleve una reproducción de cualquier obra de Murillo. Desde los Niños comiendo melones hasta sus inmaculadas. Tanto con el grabado y la imprenta como con las nuevas tecnologías propias de la época de la reproductibilidad técnica las imágenes que el pintor sevillano creó han sido sistemáticamente instrumentalizadas por los sistemas de poder. La muestra intenta desligar la imagen e imágenes de Murillo de sus usos pasados más punitivos y reaccionarios.

La muestra, Aplicación Murillo. Materialismo, charitas, populismo (diciembre 2018-marzo 2019) se disemina en diferentes espacios expositivos y no expositivos ${ }^{1}$ de Sevilla, estructurados en tres itinerarios: Materialismo, Charitas y Populismo, además de un conjunto de operaciones específicas para con los espacios y el pintor. Aplicación Murillo más que una exposición en el cubo blanco [1] es una performance: ya no solo por el modo en el que el/la visitante tiene que recorrer el total de los espacios sino por la capacidad de producir enunciados en el instante mismo que se contempla la exposición. Aunque parezca complejo es bastante sencillo. Ciertamente, los comisarios pretenden hacer vivir a las visitantes una experiencia performática al hacernos transitar $^{2}$ por la ciudad buscando las salas expositivas, entrar a los espacios eclesiásticos donde se encuentran algunas operaciones y vivir, en cierto modo, el aire barroco de Sevilla. Por otra parte la exposición, como todas, funciona como dispositivo foucaultiano: un conjunto de redes conformadas por elementos heterodoxos que entrelazados entre sí configuran una verdad y una realidad. La de Aplicación, hacernos ver a Murillo y el barroco como una fiesta de radicalidad y subversión, obviando el resto de problemas que las políticas del barroco produjeron para el control de los cuerpos y los modos de vidas siguientes.

Dichas políticas eran más que evidentes en el recorrido expositivo que nos proponían: alabar el espíritu «cari-

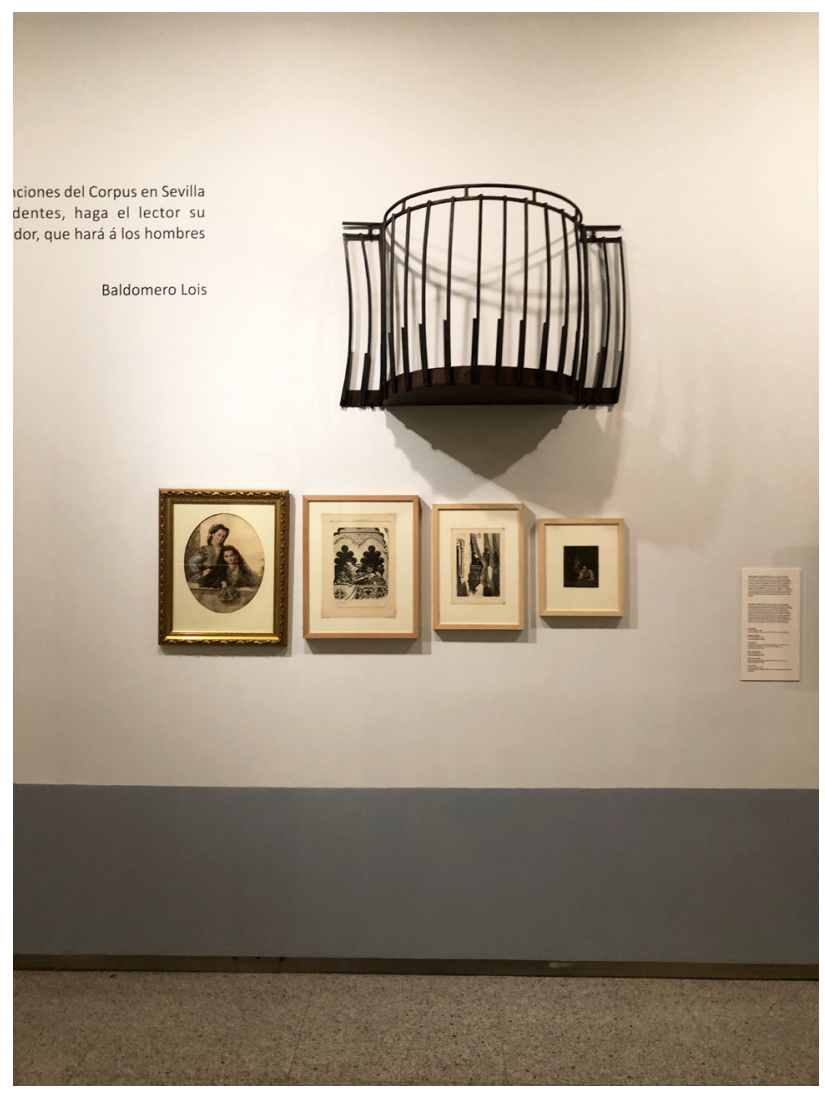

1. Composición, varios artistas, en la Sala Atín Aya

tativo» de Murillo, hacerlo ver más como un objeto popular que un miembro distinguido del Parnaso de pintores. Y con esto no pretendo referirme a una banalización del pintor sino a poder verlo más como una pieza clave del acervo cultural sevillano-nacional y como una figura clave de la modernidad.

No es la primera vez que en el territorio español se celebran exposiciones aniversarias sobre artistas del Siglo de Oro. Si miramos una de las más recientes, y con mayor presupuesto orquestada desde el Ministerio de Cultura y bajo la batuta del Prado, las lógicas que organizaron el proyecto y su flagship-show, El Greco y la pintura moderna, fueron totalmente diferentes: mientras la del pintor cretense 


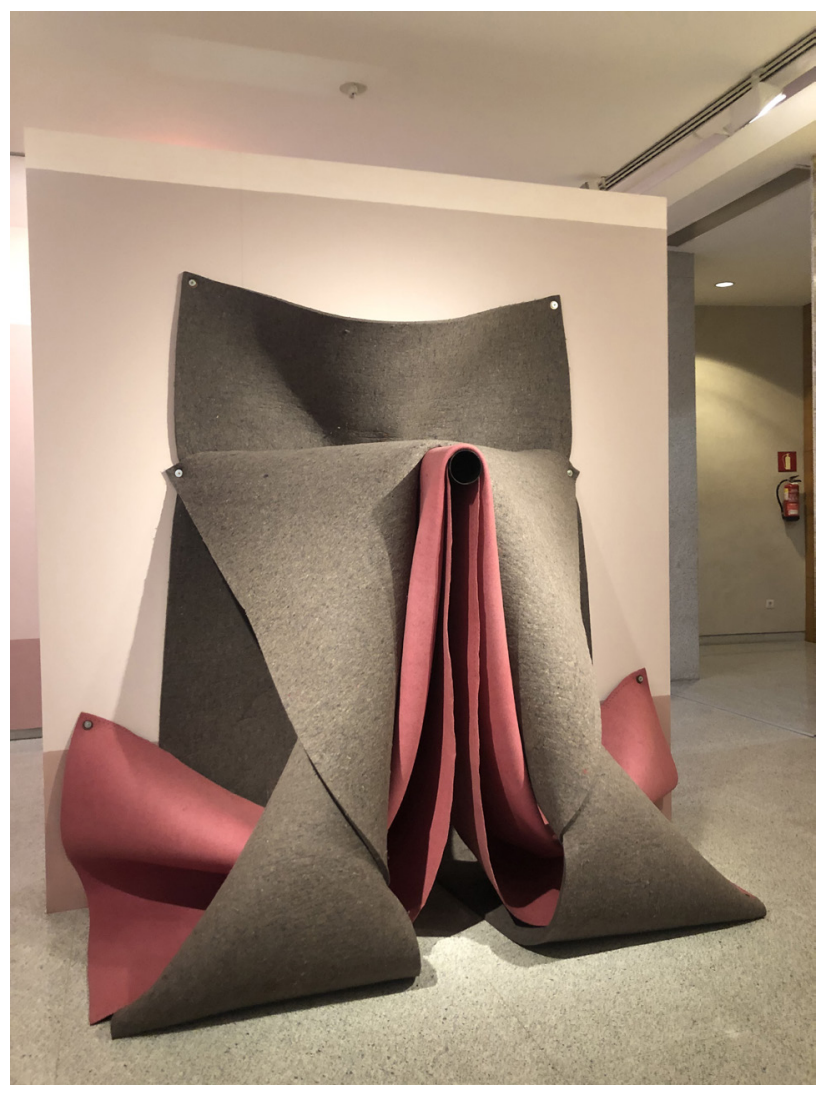

2. Obra House of Vetii (1983), de Robert Morris, en la Sala Atín Aya (Charitas)

ponía en relación la influencia plástico-técnica de éste con los pintores y artistas de Vanguardia y de mitad de siglo, la muestra comisariada por Pedro G. Romero et al. intentaba aplicar un giro diferente a las miradas del pintor, más allá de su plástica. Aplicación Murillo, se configura como una suerte de influencia, supervivencia -Nachleben- y limpieza.

Esta suerte conceptual, sin duda, reside en la capacidad teórica del artista y pensador Pedro G. Romero quien firma el texto estructural de la exposición, pese a ser tres los comisarios, además: Luis Martínez Montiel y Joaquín Vázquez. Tanto sus propias exposiciones individuales como sujeto-artista o curador $^{3}$ lo corroboran. El trabajo llevado a cabo con el Archivo FX le ha servido para desarrollar un conocimiento extenso y profundo de diferentes metodologías sobre la imagen y el tiempo histórico: la genealógica y arqueológica propia de Foucault, la desarrollada por Aby Warburg -posteriormente también trabajada por Agamben y Didi-Huberman- y las diferentes tesis sobre las temporalidades, la Historia y la reproductibilidad técnica de la obra de arte de Walter Benjamin. Todo este conjunto epistemológico-artístico vertebra el eje conceptual de la exposición y sin duda vira críticamente los estudios sobre el pintor sevillano. Pedro G. es un nadador experto del río de las imágenes y sabe bien que no siempre nos vamos a sumergir en el mismo río; con este principio la exposición puede tornarse áurea, con el problema, a veces, de poder tornarse pétrea.

Pretender lanzar múltiples interpretaciones a la obra desde un pensamiento situado es bastante interesante, especialmente dentro del campo curatorial pero ¿realmente es éste uno de los motivos de la exposición? o ¿es más bien, como decíamos antes, una técnica de producción de verdad en cuanto al conjunto de obras allí recogidas y la figura del pintor sevillano? Este tipo de interpretaciones pueden alejarnos de ciertas cuestiones que pueden consistir, siguiendo a Sontag, «en mostrar cómo es lo que es, inclusive qué es lo que es y no en mostrar qué significa»" Son muchas las obras que nos hacen pensar sobre la existencia de esta relación y si no es algo extremadamente forzado. Ejemplo sencillo puede ser la relación con la obra de Pepe Espaliú. Con qué certeza podemos afirmar que el artista cordobés se inspiró en la caridad murillesca, o incluso en algunas obras concretas del pintor cuando realmente, como recogen entrevistas del autor y decenas de trabajos sobre él, sus Carrying [2] y su obra posterior al contagio estaban relacionados plenamente con los afectos y los cuidados que los enfermos de sida de Nueva York tuvieron que tejer entre ellos a causa de la estigmatización y el rechazo ejercido por parte del cuerpo clínico y la sociedad a los contagiados. Hacer ver una relación entre la caridad barroca y el activismo y las políticas de cuidados que el sida creó es lo mismo que afirmar, como Hillary Clinton hizo, que Nancy Reagan fue quien convirtió la crisis de la enfermedad en un debate nacional.

Quizá, Murillo sí que fue un activista con sus pinturas ¿pero acaso era un activismo puro? O era un tipo de activismo, de caridad, homeopática, algo curativo en pequeñas cantidades y destructivo en grandes. Puede que sea ese el problema de ensalzar la figura cuidadora del Barroco. Es cierto que nadie puede negar la existencia de un ejercicio caritativo durante la Sevilla barroca, pero la cuestión no es simplemente esa: mientras que se gana a Dios por la caridad se están permitiendo lógicas de muerte y exclusión con el 
otro, y ya no solo al otro enfermo, queer, sin-techo o diverso funcional, al que el extramuros era su locus particular; sino también al otro extramuros, al ultramar, donde se estaban asesinando, cometiendo un genocidio para que en la metrópolis pueda llevarse a cabo la repetición del gesto que permite a la pintura de Murillo alcanzar una gran potencia y significado propio.

Lo recogido en la exposición, sin duda, es un ejercicio inteligente desde una perspectiva un tanto centrífuga con Murillo [3], y que a veces peca de más de una idealización nacional-identitaria, y por lo tanto de una limpieza de la imagen del pintor, que de una mirada crítica. La exposición es un goce para quien la visite, al menos por la calidad del conjunto de obras allí recogidas y por mucho de los textos redactados, otras tantas van a pensar que se le toma el pelo, pero sin duda es una exposición no antes vista en el panorama expositivo de España. Por acabar con Sontag, en Aplicación Murillo, más que una hermenéutica se ha desarrollado una picaresca del arte.

\section{Álex Martín Rod}

Creador e investigador independiente

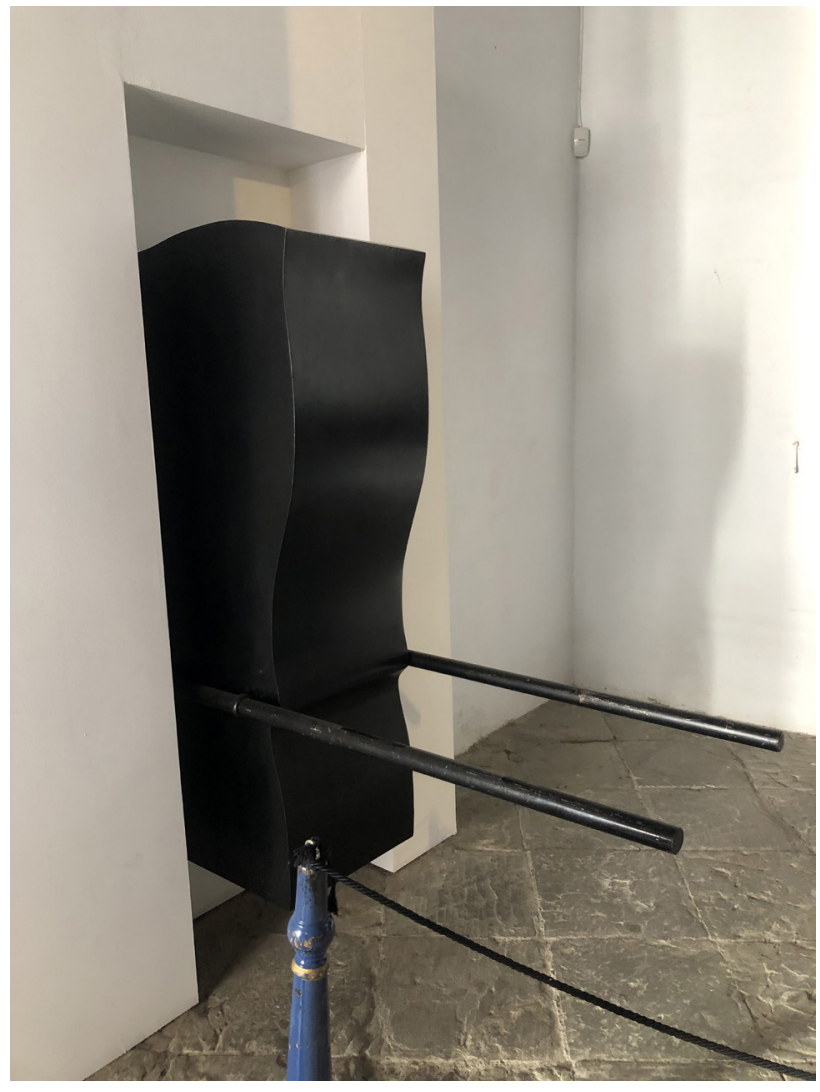

3. Obra Carrying (1993), de Pepe Espaliú, instalada en el Hospital de la Caridad

\section{Notas}

1 La exposición queda dividida en varios espacios de la ciudad de Sevilla. Los tres principales son Sala Santa Clara (Materialismo), Sala Atín Aya (Charitas) y Cicus (Populismo) además de los Hospitales de la Caridad y Venerables, la Facultad de Bellas Artes e ICAS (Factoría Cultural). Sirva esta nota para recoger el descontento con el precio total de la muestra que asciende a casi $30 €$, algo paradójico en relación con el discurso versado en la misma.

2 Véase la crítica a la misma exposición en la presente edición de la investigadora Alicia Navarro.

3 Véase: La noche española en el MNCARS junto a Patricia Molins, Máquinas de vivir con María García en CentroCentro o Poesía Brossa con Teresa Grandas en el MACBA.

4 SONTAG, Susan (1984), Contra la interpretación y otros ensayos, Seix-Barral, Barcelona, p. 27. 
Y Sevilla volvió a ser Babilonia por un día... Derivas, Theatrum, Arquitectura en Aplicación Murillo

El Barroco [...] el más pequeño elemento de laberinto es el pliegue, no el punto. Gilles Deleuze, 1988

¡Oh, gran máquina Sevilla! ¿Esto solo os maravilla?

Es a Babilonia igual. Lope de Vega, $1603^{2}$

Uno casi siempre visita Sevilla, sea oriundo o no, sabiendo que se perderá por sus calles. Como flâneur obligado o deriveante -no situacionista sino sitiado- por su orgánico entramado urbano que rezuma la pasada riqueza sensual de su barroquismo arquitectónico. Pero como afirma Deleuze «El Barroco no remite a una esencia, sino más bien a una función operatoria, a un rasgo»³. Góngora la llamó «gran Babilonia», puede que en este concepto deleuziano radique una de las causas, esa puerta de las Indias cuyo puerto se llenó de las riquezas que de ellas derramaron propiciando una urbe de «ricos escalones enladrillados de plata» ${ }^{4}$-poética imagen gongoriana necesariamente releída hoy desde la crítica decolonial-, en constante tensión con la pobreza presente en sus estratificadas esferas cual organigrama humano de desigualdad. Que fue plasmado por las plumas de los literatos barrocos quienes ya vieron a la urbe sevillana -«no ciudad sino urbe» que solía reprobar Lope de Vega-, como el gran escenario de un auténtico teatro o el tópico literario del Theatrum mundi, mostrando la vida sevillana como una pieza teatral. En eso y en otras cosas consiste, cual dispositivo museístico teatral y arquitectónico relativo a la práctica expositiva del hoy, Aplicación Murillo. Materialismo, Charitas, Populismo ${ }^{5}$. Así que al igual que Didi-Huberman en su epígrafe sobre constelaciones del anacronismo nos preguntamos, «¿Programa ambicioso -y en estos tiempos de positivismo reinante paradojal-? Quizás».

Emulando aquel verso de Quevedo, que bien podría referirse a Sevilla, «Llegamos a Babilonia / un miércoles por la noche» ${ }^{6}$. A la mañana siguiente nos esperaba uno de esos días propios de la latitud sur, ese clima geográfico-telúrico del que Celestino Espinosa afirma es la compensación de felicidad que hace aceptar la desgracia sin caer en la desesperación ${ }^{7}$. Sin duda el día perfecto para una muestra que reclamaba devoción. Aunque el problema de ese tipo de muestras es, precisamente, que uno se acerca a ellas como el ferviente a la iglesia. Pero ya dijo Adorno que «El museo y el mausoleo no están unidos solo por una asociación fonética. Los museos son como panteones de obras de arte»8. En esas estábamos cuando la primera problemática se nos presentó ¿por dónde empezar?, teniendo en cuenta que en la actualidad museo e iglesia posen la misma esencia sacralizadora, la respuesta vino sola, derivemos.

Aunque no podíamos ser deriveantes puros -pues aun multiplicando sus puertas el recorrido estaba dirigido y acotado a cinco espacios- la perspectiva era excitante. En palabras de sus comisarios, Pedro G. Romero, Joaquín Vázquez y Luis Martínez Montiel, la idea central de la muestra era la circulación de Murillo entre los artistas y las estéticas del hoy. Para ello, se habían dispuesto las obras en diferentes espacios-estancia diseminados por el entramado urbano de la ciudad dentro de arquitecturas de la Sevilla barroca y la contemporánea. Por lo que el visitante debía recorrer a pie la ciudad en busca de los tesoros artísticos cual estrellas o mercancías de un cosmos aurático-capitalista cuyo centro era Murillo o su blanqueamiento. Algo que como decía el pequeño catálogo de la muestra constituye un modelo de relación más cercano al programa pictórico realizado por el propio Murillo. La idea, por tanto, era alejarnos del modelo Museo como ejemplo expositivo y buscar la interrelación entre obras, argumentos y espacios. De este modo la circulación era plural pero no infinita y libre pero con pautas. Aun así seguía pareciendo acertado pensar que la idea de deriva, definida por Debord como una de las prácticas más poéticas mediante el juego cuyo campo de acción es la vida en la ciudad, tenía un papel clave en la muestra Aplicación Murillo.

Empezamos nuestro recorrido, o peculiar deriva expositiva, en el Hospital de la Caridad situado en el barrio del Arenal. No pude evitar acordarme de Lope de Vega mientras lo recorríamos «metro a metro, escrutando su pasado [...] zona de embarque de todos los que soñaron la "aventura americana" ${ }^{9}$. El colonialismo y el cuerpo enfermo se hicieron presentes antes incluso de llegar al hospital reconvertido en espacio expositivo. Que sin darnos cuenta se erigía ante nosotros como solemne arquitectura barroca. Entramos, previo pago, en busca de la charitas cuando ni andados diez 
pasos Carrying Project de Pepe Espaliú se encontraba ante nuestra visión, dispuesto en una sala (blanca) previa y aledaña a la Iglesia dedicada a la fe y la caridad. El choque frontal resultó sumamente interesante, ciertamente, el diálogo entre arte barroco y contemporáneo se había conseguido al relacionar el sida con la peste que azotó Sevilla -sus cuerpos, calles y mentes-, pero no sin desaciertos discursivos desde lo cuir ${ }^{10}$. Nada más entrar en la iglesia su escenografía barroca nos invadió con la turbulencia deleuziana que conllevan sus materiales, esa «forma turbulenta que siempre se nutre de nuevas turbulencias y solo acaba como la crin de un caballo o la espuma de una ola» ${ }^{11}$. Allí, con mis pies pisando una tumba-mausoleo cuyo exquisito grabado en piedra constituía la cuadratura del círculo de la idea adorniana del Museo como mausoleo, las herradas y estereotipadas aunque también algo ciertas palabras de Gregorio Marañón me sobrecogieron. Cómo negar y querer renegar al mismo tiempo de que «El artista español puede representar lo feo; [...] como las llagas de los leprosos de Murillo o los cadáveres corruptos de Valdés Leal. Pero nada de esto es triste, porque está lleno de esperanza». Miré una vez más las pinturas colgadas en los muros barrocos antes de irme; hice bien, pues el resto del espacio fue fútil y sin ningún cuidado en su exposición a términos de montaje. Poner un acento tan depurado en la economía de los cuidados y no en el cuidado de cómo exponer las piezas no me pareció muy acertado.

Seguimos nuestra deriva por las calles del centro urbano de la capital andaluza hasta llegar al Espacio Santa Clara. El más rotundo y mercantilizado -expositivamente hablando- de todos. La sucesión de obras y el alto nivel discusivo de la muestra era agotador pero adictivo. Uno parecía querer más de esas neoturbulencias que como extrañas ondas formadas por pliegues barrocos y puntos contemporáneos expandidos, envolvían y perturbaban con la misma fuerza tensándose entre sí. El discurso expositivo era brillante al tiempo que mostraba sus sombras o errores que la más de las veces conformaban su propia brillantez. Aturdidos por el horror vacui de tantas piezas -fueran estas barrocas o contemporáneas- proseguimos nuestro camino hacia la Sala Atín Aya, no sin antes tomar un merecido descanso en la bulliciosa Alameda de Hércules. Una vez allí, al tiempo que recorríamos sus salas, la premisa marcada por los comisarios de diferenciar entre tres ámbitos (Materialismo en el Espacio Santa Clara, Charitas en la Sala Atín Aya y
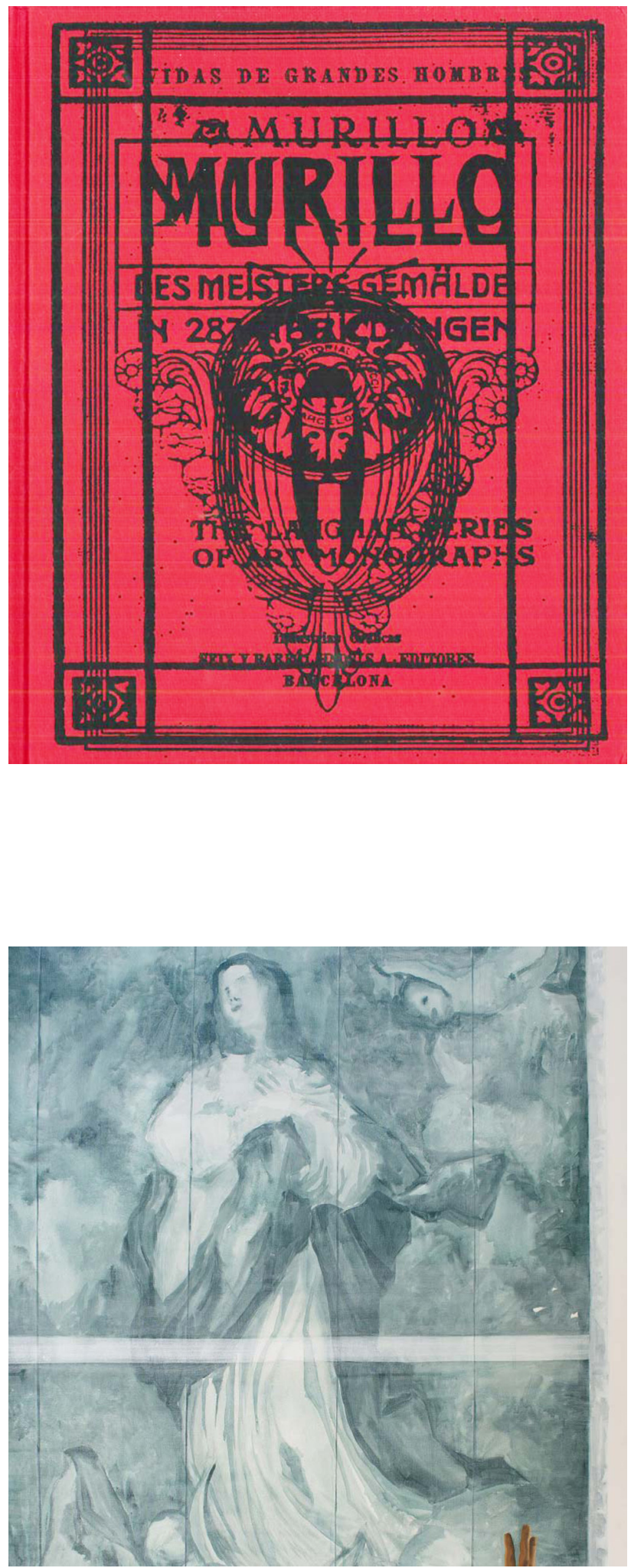
Populismo en CICUS) se iba diluyendo cada vez más como los pigmentos que Murillo diluía en las aguas del Guadalquivir para hacer sus coloridas pinturas. Al llegar a CICUS la realidad fue rotunda, los tres ámbitos recorrían y vertebraban de forma transversal, cual flecha de Santa Teresa, el cosmos de la muestra en su conjunto. A falta del Hospital de los Venerables la conclusión ya se tornaba clara, la muestra había convertido a la ciudad en un laberinto ordenable compuesto por pequeñas estancias cual constelaciones -o mónadas de Deleuze- como unidades individuales que nos mostraban una pequeña parte del discurso al tiempo que nos hablaban del cosmos expositivo en su conjunto. Una verdadera Babilonia barroca que exponía ante nosotros su confuso entramado de calles. Solo faltaba la cárcel como negocio, el censo de mendigos o niños abandonados entre crónicas de revueltas por el pan y el pillaje portuario. Aunque bien pensado, el pillaje pervivía en la judería hacía donde nos dirigíamos y el resto de males barrocos estaban presentes en las fotografías de las Misiones Pedagógicas o las telas de los cuadros de Murillo, Velázquez y Valdés Leal.

Tras transitar una estrecha y adoquinada calle de la judería, la plaza de Doña Elvira nos condujo a la imperturbable fachada del Hospital de los Venerables. Si pensábamos que con El castillo de pureza (putero y cuir) de la Sala Atín Aya o con los cuerpos subalternos dispuestos en paredes de CICUS habíamos visto lo mejor de la muestra, nos equivocábamos. El espacio de los sacerdotes Venerables se nos presentó como quintaesencia de todo lo visto anteriormente, cuando paseando por una de sus galerías superiores vimos los conceptos tensionados de lo liso y lo estriado de Deleuze y Guattari aplicados a una de las obras en tejido de Teresa Lanceta en contraposición a una vaporosa tela dorada. Que mediante un inteligente juego de miradas barrocas y contemporáneas nos escenificaba, parafraseando a Fernández Almagro, «El oro en barras de la raza y también su escoria»12. Al entrar en la sala de pintura antigua, absolutamente imbuidos por el discurso expositivo, nos pareció ver como las vírgenes, los ángeles y las santas salían de sus telas para prestar sus auráticas aureolas a la contemporaneidad instaurando esa lejanía inaproximable de Benjamin.
Cuando abrumada me asomé a uno de los balcones con barroca celosía policromada, recordé que allí mismo se emplazó el corral de comedias de Doña Elvira y en mis oídos resonaron las palabras del Director de El Público de Lorca, «iHay que destruir el teatro o vivir en el teatro! No vale silbar desde las ventanas», que automáticamente se unieron a la experiencia de deriva expositiva que estábamos viviendo. La ruptura de la cuarta pared de Lorca o Brecht, la deriva de Debord -que había vuelto a la ciudad hispalense una vez más aunque fuera en mis pensamientos- y el theatrum mundi barroco con un punto de auto sacramental 2.0 en práctica invertida, completaron el dispositivo museístico de Aplicación Murillo. ¿Había llevado Pedro G. Romero su discurso para Un Teatro sin Teatro y Archivo F.X a un nivel expositivo? Es posible. Solo faltaba Warburg y estarían todos sus fetiches, y eso que la lista es larga, pensé ¡Entonces caí! Por supuesto también estaba. Sobre todo en la lectura que ve el movimiento de las imágenes como el «bailar» de los cuerpos en la historia, corporeidades como las nuestras que inevitablemente formaban ya parte de la constelación visual de la muestra. La conclusión de que en Aplicación Murillo no se podía diferenciar entre experiencia expositiva, realidad vivencial y teatral nos colonizó, cual literatos barrocos en la Babilonia sevillana, durante días. Y así, aquella urbe máquina de Lope de Vega se unió a la máquina teatral-expositiva de la muestra auspiciada por la máquina barroca de Deleuze. Pues la experiencia expositiva que vivimos se encontraba imbricada de forma irremediable en el espacio arquitectónico y teatralizado de Sevilla, el elevado discurso comisarial -no carente de sus sombras- y el uso de herramientas expositivas distanciadas del whitecubismo pero, lamentablemente, no sin abandonarlo por completo. Al alejarnos de la ciudad, mientras divisaba su majestuoso perfil antaño presidido en altura por la Giralda ahora por el capitalismo de la Torre Pelli a la que hace años Nicho de Elche cantó una Saeta ${ }^{13}$, exclamé «joh, gran máquina Sevilla! ¿Esto solo os maravilla? Es a Babilonia igual».

Alicia Navarro Creadora e investigadora independiente 


\section{Notas}

1 DELEUZE, Gilles (original 1988, 1989), El pliegue. Leibniz o el barroco, Paidós, Barcelona, pp. 11-14.

2 SERRERA CONTRERAS, Ramón María (2007), "Lope de Vega y El arenal de Sevilla», Boletín de la Real Academia Sevillana de Buenas Letras, n. 35, pp. 149-168, p. 163.

3 DELEUZE, Gilles, op. cit., p. 11.

4 GÓNGORA, Luis de, Vuélvese a Tadeo, Perteneciente a sus Romances. v. 493-494.

5 Comisariada por Pedro G. Romero, Joaquín Vázquez y Luis Martínez Montiel, del 6 de diciembre de 2018 al 3 de marzo de 2019.

6 QUEVEDO, Francisco de (2007), Poesía burlesca. Tomo Il: Jácaras y Bailes / Francisco de Quevedo; edición, glosario y notas de Ignacio Arellano, Biblioteca Virtual Miguel de Cervantes, Alicante, p. 54.

7 ESPINOSA, Celestino (1940), «Lo flamenco», Vértice, n. ${ }^{\circ}$ 30-31, marzo-abril, p. 43.

8 ADORNO, Theodore W. (2008), Crítica de la Cultura y la Sociedad, Akal, Madrid, p. 160.

9 SERRERA CONTRERAS, Ramón María, op. cit., p. 149.

10 Para saber más véase la crítica a la misma exposición en la presente edición del investigador Alejandro Martín Rod.

11 DELEUZE, Gilles, op. cit., p. 13.

12 FERNÁNDEZ ALMAGRO, Melchor (1945), "Zuloaga y la "españolada" ", Abc, Madrid, 4 de noviembre, p. 43.

13 Saeta realizada en 2012 por Niño de Elche y Manuel Prados, pone en relación flamenco y territorio. Niño de Elche le canta desde el campanario de la Giralda a la polémica Torre Pelli, que erigiéndose en los años de la burbuja inmobiliaria se ha convertido en la edificación más alta de Sevilla, condición que ha ostentado durante más de ocho siglos la Giralda. Como recoge Ortiz Nuevo en ¿Quién me presta una escalera?, el nombre de este cante religioso procede de la palabra latina «sagitta», que significa «flecha». Las saetas, escribe Antonio Machado Álvarez «Demófilo», "Son coplas disparadas a modo de flechazos contra el empedernido corazón de los fieles». 